FESTKÖRPERPROBLEME

BAND II 



\title{
Festkörperprobleme BAND II
}

\author{
zugleich Halbleiterprobleme Band VIII
}

in Referaten des Halbleiterausschusses

des Verbandes Deutscher Physikalischer Gesellschaften

Saarbrücken 1962

Herausgegeben von

Prof. Dr. Fritz Sauter, Köln

Mit 221 Abbildungen

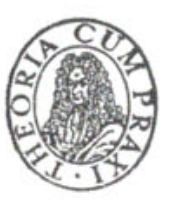

AKADEMIE-VERLAG, BERLIN 1963 
Lizenzausgabe des Verlages

Friedr. Vieweg \& Sohn, Braunschweig

Alle Rechte vorbehalten

(c) 1963 by Friedr. Vieweg \& Sohn, Braunschweig

Satz und Druck: ACO DRUCK GMBH, Braunschweig

Printed in Germany

Druckgenehmigungsnummer $202 \cdot 100 / 858 / 63$ 